\title{
Desempenho zootécnico e econômico da tilápia, linhagem GIFT-Epagri SC02, em cultivo semi-intensivo em Santa Catarina
}

\author{
Bruno Corrêa da Silva ${ }^{1}$, Haluko Massago ${ }^{2}$, Natália da Costa Marchiori ${ }^{3}$, Valdomiro Biz ${ }^{4}$ e Tatiane Carine Silva ${ }^{5}$
}

Resumo - Avaliou-se o desempenho a campo da segunda geração da linhagem de tilápia da Epagri, chamada de GIFT-Epagri SC02, nas regiões norte e médio Vale do Itajaí. Foram acompanhados os desempenhos zootécnico e econômico de dois cultivos comerciais na safra 2016/2017 e outros dois, na safra 2017/2018. Os alevinos foram provenientes da Epagri, e foram selecionados produtores nos municípios de Massaranduba, Timbó e Gaspar. A tilápia atingiu peso final entre 670 a $1.000 \mathrm{~g}$ e ciclo entre 7 a 12 meses. Os cultivos obtiveram uma produtividade anual entre 18 a $47 \mathrm{t}$ por hectare ao ano. Quanto ao desempenho econômico os cultivos obtiveram um lucro líquido entre $\mathrm{R} \$ 25$ mil a $\mathrm{R} \$ 53$ mil por hectare ao ano, com exceção do cultivo de Timbó, devido à alta conversão alimentar, consequência de problemas na sobrevivência e no manejo alimentar.

Termos de indexação: Oreochromis niloticus; melhoramento genético; conversão alimentar; viabilidade econômica.

\section{Zootechnical and economic performance of the Nile tilapia strain GIFT-Epagri SC02 in a semi-intensive culture system in Santa Catarina State}

\begin{abstract}
Grow-out performance of second-generation Epagri Tilapia strain, also called GIFT-Epagri SC02, was evaluated in the northern and middle Itajaí Valley regions. The zootechnical and economic performance of two commercial cultures for the 2016/2017 harvest and two other commercial culture for the 2017-2018 harvest was followed up. Fingerlings were derived from Epagri and producers hailed from the municipalities of Massaranduba, Timbó and Gaspar. Tilapia reached a final weight ranging between 670 and 1000g in 7-12 months. Cultivation had a productivity of $18-47$ ton $^{-1} \mathrm{y}^{-1}$ year $^{-1}$. The economic performance reached a net profit between $R \$ 25,000$ and $R \$ 53,000$ hectare year ${ }^{-1}$, except for culture in Timbó due to high feed conversion caused by problems of survival and feed management.
\end{abstract}

Index terms: Oreochromis niloticus; selective breeding; feed conversion rate; economic viability.

\section{Introdução}

A produção de tilápias representa, hoje, $55,4 \%$ da produção total de peixes no Brasil (Medeiros, 2019). Em Santa Catarina, esse número é ainda mais expressivo: as tilápias atingem $71,2 \% \mathrm{da}$ produção catarinense, totalizando 30,4 mil toneladas de peixes (SILVA et al., 2017).

Com o intuito de fomentar a atividade no estado, a Epagri dispõe, desde 2011, de um programa de melhoramento genético da tilápia, resultando no desenvolvimento da linhagem GIFT-Epagri. $O$ programa é focado em selecionar animais com maior ganho de peso e mais adaptados às condições de clima e de cultivo predominante local, isto é, subtropical e semi-intensivo arraçoado, res- pectivamente. Atualmente o programa encontra-se na sua segunda geração, com ganho genético para peso final superior a 8,4\% em relação à geração anterior (Silva et al., 2019) e com mais de 50 mil matrizes distribuídas aos aquicultores do país.

\section{Acompanhamento técnico}

A fim de avaliar o seu desempenho a campo, quatro cultivos da GIFT-Epagri SC02 (segunda geração) foram acompanhados por profissionais da Epagri; durante o período de 2016 a 2018, em três propriedades localizadas no Vale do Itajaí: Timbó (safra 2016/17), e Gaspar (safra 2017/18) (Figura 1); e Litoral Norte: Massaranduba (safras 2016/17 e 2017/18).
O povoamento foi realizado com alevino $1( \pm 0,8 \mathrm{~g}$ de peso) em todas as propriedades, mas as densidades de cultivo (número de peixes por $\mathrm{m}^{2}$ ) variariam conforme a experiência de cada produtor, a disponibilidade de água na propriedade e os recursos financeiros. $\mathrm{Na}$ propriedade de Massaranduba o produtor povoou com algumas carpas capim, cabeçuda e comum ao longo do cultivo, provenientes da própria propriedade. $\mathrm{O}$ acompanhamento foi caracterizado por visitas quinzenais ou mensais dos técnicos nas propriedades, sendo realizados os seguintes procedimentos: 1) biometria de uma amostragem de animais ( \pm 50 indivíduos) para estimação do seu crescimento e da biomassa do viveiro; 2) supervisão quanto ao uso da tabela de alimentação de tilápias (SILVA \& MARCHIORI, 2018); 3) •

Recebido em 22/4/2019. Aceito para publicação em 14/10/2019.

1 Engenheiro de Aquicultura, Dr., Centro de Desenvolvimento em Aquicultura e Pesca (Epagri/Cedap). E-mail: brunosilva@epagri.sc.gov.br.

2 Engenheira de Pesca, Dra., Centro de Desenvolvimento em Aquicultura e Pesca (Epagri/Cedap). E-mail: halukomassago@epagri.sc.gov.br.

3 Bióloga, Dr., Centro de Desenvolvimento em Aquicultura e Pesca (Epagri/Cedap). E-mail: nataliamarchiori@epagri.sc.gov.br.

${ }^{4}$ Técnico Agrícola, Epagri/Gerencia Regional de Itajaí. Email: valdomiro@epagri.sc.gov.br.

${ }^{5}$ Engenheira-agrônoma, Epagri / Gerencia Regional de Itajaí. Email: tatianesilva@epagri.sc.gov.br. 

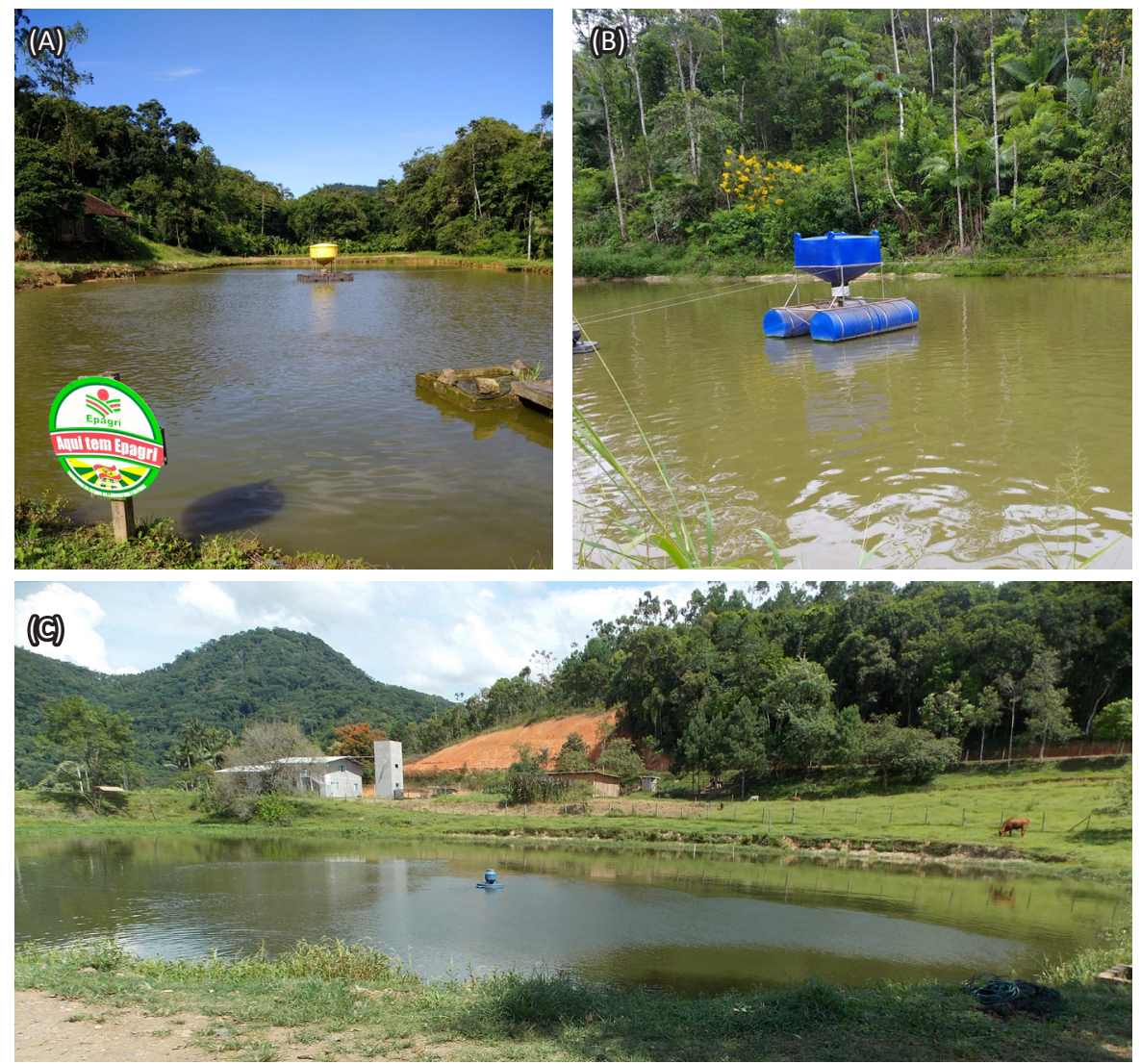

Figura 1. Propriedades acompanhadas tecnicamente pela Epagri. A -Município de Massaranduba; B -Gaspar; C-Timbó. Foto: Haluko Massago

Figure 1. Farms technically assisted by Epagri. A - Municipality of Massaranduba; B Gaspar; C-Timbó. Photo: Haluko Massago

Orientações técnicas quanto ao manejo adotado (adubação, aeração, correção da alcalinidade e qualidade de água), presença de organismos indesejáveis no cultivo, floração de microalgas, entre outros manejos.

Ao final dos cultivos, foram calculados os parâmetros zootécnicos (peso final, ganho de peso diário, sobrevivência (\%), conversão alimentar e produtividade) e os econômicos (lucro líquido, rentabilidade e preço mínimo de venda, bem como os custos variáveis, fixos e totais de produção). Para facilitar as comparações, os dados de produtividade e lucro líquido foram extrapolados para hectare por ano.

\section{Resultado zootécnico dos cultivos}

Os dados estão descritos na Tabela 1. No geral, os cultivos apresentaram produtividades muito acima da média produzida no estado. Segundo Silva et al. (2017), no ano de 2015 a produtividade média anual das pisciculturas em Santa Catarina foi de $7.400 \mathrm{~kg} \mathrm{ha}^{-1}$, enquanto nos cultivos acompanhados neste trabalho variou entre 18 e $47 \mathrm{t}$ por hectare. 0 peso médio na despesca (670 a 1.000g) variou de acordo com o destino de venda (frigorífico ou pesquepague) e da época do ano (frigoríficos e pesque-pague dão preferência por tilápias com maior peso em épocas com maior disponibilidade de produto).

$\mathrm{O}$ ganho de peso diário (GPD) variou de 2,81 a 3,21g dia-1. Durante o verão (povoamento até 1 a quinzena de maio), o GPD médio foi de $3,77 \mathrm{~g} \mathrm{dia}^{-1}$ $\left(3,45\right.$ a $\left.4,28 \mathrm{~g} \mathrm{dia}^{-1}\right)$, enquanto no inverno ( $2^{\mathrm{a}}$ quinzena de maio até a despesca) foi de $1,78 \mathrm{~g} \mathrm{dia}^{-1}\left(1,42\right.$ a $\left.2,23 \mathrm{~g} \mathrm{dia}{ }^{-1}\right)$. 0 GPD não diminuiu em função das maiores densidades de cultivo, pelo contrário: os cultivos acompanhados com as maiores densidades de estocagem obtiveram maior GPD. Isto ocorre devido às melhores condições de qualidade de água e manejo alimentar impostas pelo produtor durante o cultivo.

As taxas de sobrevivência dos cultivos foram satisfatórias, acima de $80 \%$, com exceção da propriedade de Timbó. Esta propriedade apresentou baixas taxas de sobrevivência em toda sua fazenda na safra de 2016/2017. Suspeita-se que a grande incidência de pássaros na propriedade, bem como a presença de girinos de rã-touro na água antes do povoamento, possam ter relação direta com a baixa sobrevivência devido à predação. Isto resultou em excesso de arraçoamento durante o cultivo em função do erro na estimação de biomassa do viveiro. Consequentemente, a conversão alimentar nessa propriedade foi acima do esperado, prejudicando também o desempenho econômico do cultivo.

O cultivo na propriedade de Massaranduba na safra de 2016/2017 também apresentou conversão alimentar alta $(>1,5)$. Com aproximadamente três meses de cultivo o alimentador automático do viveiro que estava sendo acompanhado na propriedade, acidentalmente foi acionado durante a madrugada, despejando cerca de $500 \mathrm{~kg}$ de ração (20 sacos) que não foram consumidos pelos peixes. Além do desperdício da própria ração, a qualidade da água do viveiro foi prejudicada, interferindo negativamente na conversão alimentar e no GPD.

\section{Resultado econômico dos cultivos}

Os dados econômicos dos cultivos estão descritos na Tabela 2. Podemos observar que há dois fatores importantes que contribuíram para que os produtores obtivessem um menor custo de produção por quilo de peixe produzido: a produtividade e a conversão alimentar. A maior produtividade ocasionou uma diluição dos custos fixos, que foram em torno de $\mathrm{R} \$ 15.000,00$ por hectare ao ano. Já a menor conversão alimentar esteve associada a uma redução significativa no custo de produção variável (CV), já que nestes cultivos a ração representou $77,6 \%$ do $\mathrm{CV}$.

O preço de venda dos animais cultivados variou significativamente em função do destino final. Enquanto os animais destinados ao pesque-pague foram vendidos por $\mathrm{R} \$ 5,50$ o quilo, os 
Tabela 1. Dados zootécnicos de quatro cultivos comerciais de tilápia, linhagem GIFT-Epagri SC02, acompanhados durante 2016 a 2018

Table 1. Zootechnical performance of four commercial cultures of second generation Epagri Tilapia strain (GIFT-Epagri SCO2) during 2016 to 2018

\begin{tabular}{ccccc}
\hline \hline $\begin{array}{c}\text { Propriedade } \\
\text { (Município) }\end{array}$ & Massaranduba & Timbó & Massaranduba & Gaspar \\
\hline \hline Safra & $2016 / 17$ & $2016 / 17$ & $2017 / 18$ & $2017 / 18$ \\
\hline Área do viveiro $\left(\mathrm{m}^{2}\right.$ ) & 1.800 & 3.750 & 1.800 & 1.000 \\
\hline No peixes povoados & $9.250^{1}$ & 9.000 & $9.180^{3}$ & 3.000 \\
\hline Densidade (peixe. $\mathrm{m}^{-2}$ ) & 5,14 & 2,40 & 5,10 & 3,00 \\
\hline Data povoamento & $02 / 12 / 2016$ & $07 / 12 / 2016$ & $14 / 11 / 2017$ & $14 / 11 / 2017$ \\
\hline Dias de cultivo & 298 & 209 & 323 & 356 \\
\hline Peso final (g) & $850^{2}$ & 671 & $980^{2}$ & 1.000 \\
\hline GPD (g.dia ${ }^{-1}$ ) & $2,85^{2}$ & 3,21 & $3,03^{2}$ & 2,81 \\
\hline Sobrevivência (\%) & 83,4 & 71,2 & 94,5 & 80,3 \\
\hline Conversão alimentar & 1,65 & 1,71 & 1,47 & 1,43 \\
\hline Produtividade $\left(\mathrm{kg} \mathrm{ha}^{-1}\right.$ ano $^{-1}$ ) & $40.533^{4}$ & $18.685^{4}$ & $47.716^{4}$ & $22.789^{4}$ \\
\hline \hline
\end{tabular}

${ }^{1}$ Povoamento de 9.000 tilápias e 250 carpas (comum, cabeçuda e capim). ${ }^{2}$ Peso final e ganho de peso diário (GPD) apenas das tilápias. ${ }^{3}$ Povoamento de 9.000 tilápias e 180 carpas (comum, cabeçuda e capim). ${ }^{4}$ Este dado levou em consideração o tempo para preparação dos viveiros.

destinados a frigoríficos saíram por $\mathrm{R} \$ 4,60$ o quilo pago ao produtor.

Os cultivos de tilápia da linhagem GIFT-Epagri SCO2 obtiveram rentabilidades de 25 a $31 \%$, com exceção da propriedade de Timbó. Isto se deu por causa da baixa sobrevivência e a alta conversão alimentar, resultando no alto custo de produção. Além disso, esse produtor possui uma limitação de água na propriedade, o que limita consequentemente a produtividade. Porém, mesmo com baixa rentabilidade, não houve descapitalização do produtor, já que para o cálculo do custo de produção foi levado em consideração a deprecia- ção e a manutenção da infraestrutura, além do salário e dos encargos trabaIhistas poupados pelo uso de mão de obra do próprio produtor durante o cultivo. Geralmente estes custos não são considerados pelos piscicultores, mas são importantes para que não haja perdas econômicas da atividade em longo prazo.

\section{Considerações finais}

A tilápia-do-nilo, linhagem GIFTEpagri SC02, mostrou bons resultados de desempenho zootécnico a campo. Os autores recomendam que os pro-

Tabela 2. Dados econômicos de quatro cultivos comerciais de tilápia, linhagem GIFT-Epagri SC02, acompanhados durante 2016 a 2018

Table 2. Economic performance of four commercial cultures of second generation Epagri Tilapia strain (GIFT-Epagri SCO2) during 2016 to 2018

\begin{tabular}{|c|c|c|c|c|}
\hline Produtor (Município) & Massaranduba & Timbó & Massaranduba & Gaspar \\
\hline Safra & $2016 / 2017$ & $2016 / 2017$ & 2017/2018 & $2017 / 2018$ \\
\hline Custo variável $\left(\mathrm{R} \$ \mathrm{~kg}^{-1}\right)$ & 3,78 & 3,80 & 3,30 & 3,35 \\
\hline Custos fixos $\left(\mathrm{R} \$ \mathrm{~kg}^{-1}\right)$ & 0,41 & 0,75 & 0,33 & 1,03 \\
\hline Custo total $\left(\mathrm{R} \mathrm{kg}^{-1}\right)$ & 4,19 & 4,55 & 3,63 & 4,38 \\
\hline $\begin{array}{l}\text { Preço de venda } \\
\quad\left(\mathrm{R} \$ \mathrm{~kg}^{-1}\right)\end{array}$ & 5,50 & 4,60 & $4,60^{1}$ & 5,50 \\
\hline $\begin{array}{l}\text { Lucro líquido } \\
\left(\mathrm{R} \$ \mathrm{ha}^{-1} \mathrm{ano}^{-1}\right)^{2}\end{array}$ & $53.097,81$ & 934,23 & $47.866,84$ & $25.523,52$ \\
\hline Rentabilidade (\%) & 31,26 & 1,10 & 27,64 & 25,57 \\
\hline
\end{tabular}

${ }^{1}$ As carpas foram vendidas a $\mathrm{R} \$ 5,50$ o quilo. ${ }^{2}$ Este dado levou em consideração o tempo para preparação dos viveiros.

dutores trabalhem com produtividades finais de 20 a 50t por hectare, ou seja, 2 a 6 peixes por metro quadrado, dependendo do destino da venda e, consequentemente, do peso médio final na despesca. Para isso, contudo, é importante o monitoramento do crescimento dos peixes durante o cultivo e dos parâmetros de qualidade de água através de biometrias e análises periódicas, adequando os manejos às boas práticas. Com isso, o produtor conseguirá atingir as produtividades indicadas, com conversões alimentares entre 1,3 a 1,5, alcançando assim uma alta rentabilidade do cultivo. Além disso, é necessário o uso adequado de aeradores, uma rede de energia segura com uso de gerador emergencial, entre outras práticas de manejo preconizadas pela Epagri.

\section{Agradecimentos}

Agradecemos aos técnicos e operários rurais (Silvano Garcia, Leandro Bortoli, João Burg, Emídio Sant'anna de Lara, Silvio Demarch Filho e Fernando Lemos), que auxiliam no desenvolvimento das pesquisas em piscicultura da Epagri/Cedap. À técnica da Epagri do município de Massaranduba, Cíntia Regina Veiga, pelo apoio nos acompanhamentos técnicos, e aos piscicultores Marcelo Luchetta, Fernando Stolf, Ofélia Campigotto e Paulo Marangoni, que gentilmente se dispuseram a realizar esse trabalho em suas propriedades.

\section{Referências}

MEDEIROS, F. (Coord.). Anuário Brasileiro da Piscicultura Peixe Br, 148p., 2019.

SILVA, B.C.; GIUSTINA, E.G.D.; MARCHIORI, N.C.; MASSAGO, H.; SILVA, F.M. Desempenho produtivo da piscicultura catarinense em 2015. Florianópolis: Epagri. (Documento, 268), 2017. 17 p.

SILVA, B. C.; MARCHIORI, N. C. Importância do manejo alimentar na criação de tilápia. Florianópolis: Epagri, 2018. 16 p.

SILVA, B.C.; MARCHIORI, N.C.; SILVA, F.M.; MASSAGO, H. Ganho genético após uma geração de seleção individual para peso final e variáveis morfométricas em tilápia. Revista de Ciências Agroveterinárias, Lages, v.18, n.1, p.103-110, 2019. 